\title{
Discovering the Meaning of Fadhilaturrahmi's Work
}

\section{Adib Rifqi Setiawan}

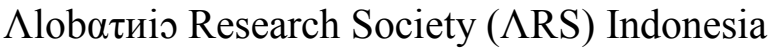

alobatnic@gmail.com

\begin{abstract}
This research aims to explore Fadhilaturrahmi's profile nor study academic journals of her individual work in educational research. This research using qualitative approach descriptive category with a phenomenological design. Data was collected using naturalistic observation, content analysis, and retrospective interviews techniques. Data's validity, reliability, and objectivity checked by using triangulation and external audit techniques.
\end{abstract}

Keywords: Academic Journals; Educational Research; Fadhilaturrahmi; 


\section{References}

Abdullah, M. (2010, Maret 6). Publikasi dan Paten adalah Hasil Samping Riset. Dipetik Mei 2, 2020, dari Mari Menjadi Lebih Baik:

http://youmikra.blogspot.com/2010/03/publikasi-dan-paten-adalah-hasil.html

Abdullah, M. (2010, Maret 24). Riset yang Terukur dan Terget yang Jelas. Dipetik Mei 4, 2020, dari Mari Menjadi Lebih Baik: http://youmikra.blogspot.com/2010/03/risetyang-terukur-dan-terget-yang.html

Abdullah, M. (2010, Maret 3). Riset/Publikasi/Paten: Bukan Sekedar Dana, tetapi Juga Komitmen. Dipetik Mei 1, 2020, dari Mari Menjadi Lebih Baik: http://youmikra.blogspot.com/2010/03/risetpublikasipaten-bukan-sekedar-dana.html

Abidin, M. (2012). Gagasan dan Gerak Dakwah Mohammad Natsir: Hidupkan Dakwah Bangun Negeri. Yogyakarta: Gre Publishing.

Almaany. (2020, Mei 4). ترجمة و معنى الرَّحْم في قاموس عربي اندونببسي Dipetik Mei 4, 2020, dari Almaany: https://www.almaany.com/ar/dict/ar-

id/\%D8\%A7\%D9\%84\%D8\%B1\%D9\%91\%D9\%8E\%D8\%AD\%D9\%92\%D9\%85

Almaany. (2020, Mei 4). قاموس عربي انجليزي بترجمة و معنى فضيلة في قاموس المعاني. Dipetik Mei 4, 2020, dari Almaany: https://www.almaany.com/ar/dict/aren/\%d9\%81\%d8\%b6\%d9\%8a\%d9\%84\%d8\%a9

Almaany. (2020, Mei 4). ترجمة و معنى فضيلة في قاموس عربي اندونبيسي Dipetik Mei 4, 2020, dari Almaany: https://www.almaany.com/ar/dict/arid/\%d9\%81\%d8\%b6\%d9\%8a\%d9\%84\%d8\%a9

Almaany. (2020, Mei 4). معجم عربي عربي تعريف و معنى فضيلة في معجم المعانسي الجامع. Dipetik Mei 4, 2020, dari Almaany: https://www.almaany.com/ar/dict/arar/\%D9\%81\%D8\%B6\%D9\%8A\%D9\%84\%D8\%A9

Anderson, L. W., \& Krathwohl, D. R. (2001). A Taxonomy for Learning, Teaching, and Assessing: A Revision of Bloom's Taxonomy of Educational Objectives. New York City: Longman.

BBC. (2010, Januari 4). World's tallest building opens in Dubai. BBC.

Bloom, B. S., Engelhart, M. D., Furst, E. J., Hill, W. H., \& Krathwohl, D. R. (1956). Taxonomy of Educational Objectives: The Classification of Educational Goals. Handbook I: Cognitive Domain. New York City: David McKay Company.

Bowi, J. B. (2019, April 16). Seruan Ketum PSI: Habis nyoblos makan babi sama-sama. Dipetik Mei 2, 2020, dari Facebook John Bon Bowi: http://archive.fo/Y9wgI

Chelsea FC. (2018, 9 Maret). Gianfranco Zola - Chelsea Legends - Chelsea FC. Dipetik Mei 2, 2020, dari Chelsea FC: https://shedwall.chelseafc.com/player/gianfranco-zola/

Eun-ji, J. (2016, Maret 28). GI를 사랑해주시고 응원해주신 모든분들 감사드려요 진심으로. 그동안 너무 행복했어요Dua hati 저는 또 다른 새로운 모습으로 인사드릴게요 잠시만 안녕Wajah menikmati makanan \#gi\# 은지. Dipetik Mei 4, 2020, dari Twitter @gi_eunji92: https://twitter.com/gi_eunji92/status/714141645395009536

Fadhilaturrahmi. (2010, November 14). Ilmu dan Hikmah | Fadhilaturrahmi ZA. Dipetik Mei 5, 2020, dari Ilmu dan Hikmah | Fadhilaturrahmi ZA: https://bundoku.wordpress.com/

Fadhilaturrahmi. (2011). Peningkatan Hasil Belajar Siswa pada Materi Jaring-Jaring Balok dan Kubus dengan Pendekatan Contextual Teaching and Learning (CTL) Siswa Kelas IV SDN 05 Air Tawar Barat. Kota Padang: Universitas Negeri Padang (UNP).

Fadhilaturrahmi. (2012, Februari).Fadhilaturrahmi ZA (@Fadhilah_ZA_) - Twitter. Dipetik Mei 1, 2020, dari Twitter: https://twitter.com/fadhilah_za_ 
Fadhilaturrahmi. (2012, Maret).Fadhilaturrahmi ZA (@Fadhilaturrahmi)|Twitter. Dipetik Mei 1, 2020, dari Twitter: http://twitter.com/fadhilaturrahmi

Fadhilaturrahmi. (2012, November 29). Menyibak Makna Sebuah Skripsi. Dipetik Mei 2, 2020, dari Ilmu dan Hikmah | Fadhilaturrahmi ZA:

https://bundoku.wordpress.com/2013/05/06/menyibak-makna-sebuah-skripsi/

Fadhilaturrahmi. (2014). Pengaruh Pembelajaran Kooperatif Tipe STAD dan GI Terhadap Peningkatan Kemampuan Koneksi dan Komunikasi Matematik Siswa Sekolah Dasar. (W. \&. Turmudi, Penyunt.) Bandung: Universitas Pendidikan Indonesia.

Fadhilaturrahmi. (2014, Mei 7). Problematika Rekruitmen Guru di Indonesia. Dipetik Mei 5, 2020, dari Ilmu dan Hikmah | Fadhilaturrahmi ZA:

https://bundoku.wordpress.com/2014/05/07/problematika-rekruitmen-guru-diindonesia/

Fadhilaturrahmi. (2016). Pengaruh Pembelajaran Kooperatif Tipe STAD dan GI terhadap Peningkatan Kemampuan Komunikasi Matematik Siswa Sekolah Dasar. Dalam A. Jupri, I. Cahyani, \& V. A. Ariawan (Penyunt.), Prosiding Seminar Nasional Pendidikan Dasar "Pengembangan Kemampuan Berpikir Kritis, Kreativitas, Komunikasi, dan Kolaborasi dalam Pembelajaran Abad 21: Inovasi Pembelajaran Abad 21". 1, hal. 95-101. Bandung: Universitas Pendidikan Indonesia (UPI).

Fadhilaturrahmi. (2017). Fadhilaturrahmi - SINTA - Science and Technology Index. Dipetik Mei 1, 2020, dari SINTA - Science and Technology Index:

http://sintadev.ristekdikti.go.id/authors/detail?id=5978277\&view=overview

Fadhilaturrahmi. (2017, Mei 9). Fadhilaturrahmi Fadhilaturrahmi - Pengutipan Google Scholar. Dipetik Mei 5, 2020, dari Google Scholar: https://scholar.google.co.id/citations?user=uze1G-UAAAAJ\&hl=id

Fadhilaturrahmi. (2017, Oktober 17). Lingkungan Belajar Efektif Bagi Siswa Sekolah Dasar. Jurnal Basicedu, 1(2), 76-84.

Fadhilaturrahmi. (2017, Mei 1). Penerapan Metode Mind Mapping Untuk Meningkatkan Hasil Belajar Mahasiswa Semester IIA PGSD Matakuliah Pendidikan Matematika SD Kelas Rendah. Cendekia : Jurnal Pendidikan Matematika, 1(1), 112-121.

Fadhilaturrahmi. (2017). Penerapan Pendekatan Matematika Realistik Untuk Meningkatkan Hasil Belajar Mahasiswa PGSD Matakuliah Pendidikan Matematika SD Kelas Tinggi. Jurnal Handayani, 7(1), 86-93.

Fadhilaturrahmi. (2017, Juli 2). Penerapan Pendekatan Saintifik Untuk Meningkatkan Kemampuan Komunikasi Matematik Peserta Didik di Sekolah Dasar. EduHumaniora : Jurnal Pendidikan Dasar, 9(2), 109-118.

Fadhilaturrahmi. (2017, Oktober 2). Pengaruh Pendekatan Open-Ended dan Pendekatan Scientifik Terhadap Kemampuan Koneksi Matematik Siswa Sekolah Dasar. Mimbar Sekolah Dasar, 4(2), 117-127.

Fadhilaturrahmi. (2017, April 18). Peningkatan Hasil Belajar Siswa pada Materi Jaring-Jaring Balok dan Kubus dengan Pendekatan Contextual Teaching and Learning (CTL) Siswa Kelas IV SDN 05 Air Tawar Barat. Jurnal Basicedu, 1(1), 1-9.

Fadhilaturrahmi. (2018, April 21). Pengaruh Pembelajaran Kooperatif Tipe STAD dan GI Terhadap Peningkatan Kemampuan Koneksi Matematik Sekolah Dasar. Jurnal Basicedu, 2(1), 160-165.

Fadhilaturrahmi. (2019, April 4). Pengaruh Pembelajaran Kooperatif Tipe GI terhadap Peningkatan Kemampuan Koneksi Matematik Siswa Sekolah Dasar. Edukatif : Jurnal Ilmu Pendidikan, 1(1), 43-55.

Fadhilaturrahmi. (2020, April 22). Pelatihan Pembelajaran E-Learning Berbasis Edmodo Bagi Guru Sekolah Dasar. Jurnal Abdidas, 1(1), 1-6. 
Fadhilaturrahmi. (2020, Mei 3-6). Percakapan WhatsApp dengan Ibu Fadhilaturrahmi. (A. R. Setiawan, Pewawancara)

Fadhilaturrahmi. (2020, Maret 14).Profil Instagram Fath (@fadhilaturrahmi_za). Dipetik Mei 5, 2020, dari Instagram: https://instagram.com/fadhilaturrahmi_za

Forlap Dikti. (2011, Oktober 8). Profil Mahasiswa - Forlap Dikti. Dipetik Mei 2, 2020, dari Forlap Dikti:

https://forlap.ristekdikti.go.id/mahasiswa/detail/NTZEMjEyQzAtNkI5OC00NDFGL UEwODQtMTFCNjU1QTkyODZC

Forlap Dikti. (2014, Juli 14). Profil Mahasiswa - Forlap Dikti. Dipetik Mei 2, 2020, dari Forlap Dikti:

https://forlap.ristekdikti.go.id/mahasiswa/detail/MjIxNDRGQjEtNTU0MS00MDgyL TgxMjgtRTMzMDIDRDk1NDQw

Forlap Dikti. (2019, Desember 31). Profil Dosen - Forlap Dikti. Dipetik Mei 2, 2020, dari

Forlap Dikti:

https://forlap.ristekdikti.go.id/dosen/detail/RTRBMjUzQ0MtMjg2MS00NzMwLUFC RDQtMDRFRTRFQTAxRkI2

Fraenkel, J. R., Wallen, N. E., \& Hyun, H. H. (2012). How to Design and Evaluate Research in Education (8th ed.). (S. Kiefer, Penyunt.) New York City: McGraw-Hil.

Galton, F. (1877, April 19). Typical Laws of Heredity. Nature, 15(390), 532-533.

Google Scholar. (2019, Juli 5). "Lingkungan Belajar" "Sekolah Dasar" - Google Scholar. Dipetik Juli 5, 2019, dari Google Scholar:

https://scholar.google.com/scholar?start=10\&q=\%22Lingkungan+Belajar\%22+\%22S ekolah+Dasar\%22\&hl=en\&as_sdt=0,5

Hake, R. R. (1998, November 4). Interactive-engagement versus traditional methods: A sixthousand-student survey of mechanics test data for introductory physics courses. American journal of Physics, 66(1), 64-74.

Hall, N. (2014, Juli 30). The Kardashian index: a measure of discrepant social media profile for scientists. Genome Biology, 15, 424.

HAMKA. (2017). Dari Perbendaharaan Lama: Menyingkap Sejarah Islam di Nusantara. Depok: Gema Insani.

Hawking, S. W. (2013). My Brief History. New York City: Bantam Books.

Hidayah, S. (2014). Peningkatan Hasil Belajar Matematika Materi Jaring-Jaring Kubus dan Balok dengan Model Contextual Teaching and Learning Kelas IV SD Semester 2 di SD 1 Gamong. Kabupaten Kudus: Universitas Muria Kudus (UMK).

Hirsch, J. E. (2005, November 7). An index to quantify an individual's scientific research output. Proceedings of the National Academy of Sciences of the United States of America, 102(46), 16569-16572.

Ilmiyah, S. (2020, Februari 11). Surotul Ilmiyah - PBNU Menjawab Tantangan Virus Corona. Dipetik Mei 4, 2020, dari YouTube alobatnic: https://youtu.be/SPdc4WT8BCg

Ilmiyah, S. (2020, Maret 22). Surotul Ilmiyah - Upaya PBNU Mencegah Penyebaran COVID-19. Dipetik Mei 4, 2020, dari YouTube alobatnic: https://youtu.be/rYlypLWR3Qw

IRIS. (2018, September 28). Mww7.5 Minahassa Peninsula, Sulawesi. Dipetik Mei 3, 2020, dari Incorporated Research Institutions for Seismology: http://ds.iris.edu/ds/nodes/dmc/tools/event/10953070

Komarova, N. L. (2018, Desember 11). Natalia Lectures on Calculus. Dipetik Mei 5, 2020, dari YouTube alobatnic: https://www.youtube.com/playlist?list=PL8jJiYrUiGXCXUa8dZEXfbNp0BiTp9dTD 
KPU RI. (2019, April 17). Rekapitulasi Daftar Pemilih Pemilu 2019. Dipetik Mei 2, 2020, dari KPU RI:

https://www.lindungihakpilihmu.kpu.go.id/index.php/rekap/pemilih/4/13772

Krathwohl, D. R. (2002). A Revision of Bloom's Taxonomy: An Overview. Theory Into Practice, 41(4), 212-218.

Krathwohl, D. R., Bloom, B. S., \& Masia, B. B. (1956). Taxonomy of Educational Objectives: The Classification of Educational Goals. Handbook II: Affective Domain. New York City: David McKay Company.

LIPI. (2017, Maret 16). Jurnal Basicedu - ISSN LIPI. Dipetik Mei 5, 2020, dari ISSN LIPI: http://issn.lipi.go.id/issn.cgi?daftar\&1489632030\&1\&\&

LIPI. (2017, Juni 9). Jurnal Basicedu - ISSN LIPI. Dipetik Mei 5, 2020, dari ISSN LIPI: http://issn.lipi.go.id/issn.cgi?daftar\&1497018198\&1\&\&

Louisa, G. N. (2019, April 19). Video Instagram pada 16 April 2019. Dipetik Mei 20, 2020, dari Instagram Grace Natalie Louisa (@ gracenat): https://www.instagram.com/p/BwUmRffHOSP/

Mart, T. (2006, Februari 1). Counting Papers. Symmetry Magazine, 3(1), hal. 8-9.

Mart, T. (2011, Juli 29). Pembusukan Akademis. Kompas.

Mart, T. (2012, 21 Februari). Hakikat Seberkas Makalah Ilmiah. Kompas.com.

Morshead, R. W. (1965). On Taxonomy of educational objectives Handbook II: Affective domain. Studies in Philosophy and Education, 4(1), 164-170.

Mudjiarto, R. (2018, November 24). Percakapan pada 24 November 2018 di rumah Roswati Mudjiarto. (A. R. Setiawan, Pewawancara)

Mulligan, M. (2017). Under Her Spell. Waikiki: Serenity Press.

Najib, M. A. (2008, Januari 27). Soeharto Wafat. Liputan 6. (R. Silalahi, Pewawancara) SCTV.

Nola, R., \& Irzik, G. (2006). Philosophy, Science, Education and Culture. Berlin, Germany: Springer Science \& Business Media.

NTSB. (1989). Aircraft Accident Report: Delta Air Lines, Inc.; Boeing 727-232, N473DA; Dallas-Fort Worth International Airport, Texas; August 31, 1988. Washington, D.C.: National Transportation Safety Board.

Paul, R. (1992). Critical Thinking: What Every Person Needs to Survive in a Rapidly Changing World. California: Foundation for Critical Thinking.

Pearson, K. (1895, Juni 20). Note on Regression and Inheritance in the Case of Two Parents. Proceedings of the Royal Society of London, 58, 240-242.

Sari, N. I. (2013). Peningkatan Hasil Belajar Jaring-Jaring Kubus dan Balok dengan Pendekatan Contextual Teaching And Learning (CTL) di Kelas IV SD Angkasa II Lanud Padang. Padang: Universitas Negeri Padang (UNP).

Scopus. (2020, Mei 2). Scopus: Access and use Support Center. Dipetik Mei 2, 2020, dari Scopus: https://www.scopus.com/results/authorNamesList.uri?sort=count$\mathrm{f} \& \mathrm{src}=\mathrm{al} \& \mathrm{sid}=12 \mathrm{fOfe} 463 \mathrm{ad} 8055176 \mathrm{~b} 7237 \mathrm{be} 162 \mathrm{~b} 184 \& \mathrm{sot}=\mathrm{al} \& \mathrm{sdt}=\mathrm{al} \& \mathrm{sl}=29 \& \mathrm{~s}=\mathrm{AU}$ THLASTNAME\%28Fadhilaturrahmi\%29\&st1=Fadhilaturrahmi\&orcidId=\&selection PageSearch $=$ anl\&reselectAuthor=false \&activeFlag=true\&s

Setiawan, A. R. (2014, Juni 2). Melantan Warisan Kaisar Telantar. Dipetik Mei 5, 2020, dari Kirana $\Upsilon$ Azalea: https://adibrs.blogspot.com/2014/06/ibrahim.html

Setiawan, A. R. (2016, April 19). Not the Next Anyone. Dipetik Mei 5, 2020, dari

ALОВАТИІО: http://alobatnic.blogspot.com/p/maria.html

Setiawan, A. R. (2017, Februari 15). Butcah Chuniez. Dipetik Mei 2, 2020, dari АLОВАТИІО: https://alobatnic.blogspot.com/2017/02/thata.html 
Setiawan, A. R. (2017). enerapan Pendekatan Saintifik untuk Melatihkan Literasi Saintifik dalam Domain Kompetensi pada Topik Gerak Lurus di Sekolah Menengah Pertama. Bandung: Universitas Pendidikan Indonesia (UPI).

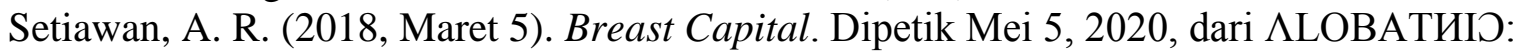
https://alobatnic.blogspot.com/2018/03/breastcapital.html

Setiawan, A. R. (2018, Agustus 8). Debut Mengajar Biologi. Dipetik Mei 5, 2020, dari АLОВАТИІО: http://alobatnic.blogspot.com/2018/08/debut-mengajar-biologi.html

Setiawan, A. R. (2018, April 10). Eny Rochmawati Octaviani. Majalah SANTRI, hal. 15-8.

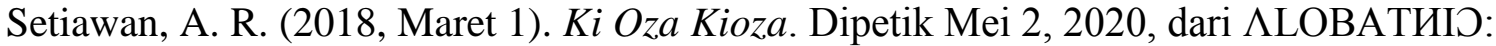
https://alobatnic.blogspot.com/2018/03/roza-lailatul-fitria-oza-kioza.html

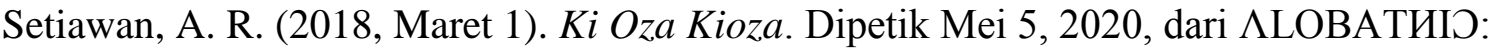
http://alobatnic.blogspot.com/2018/03/roza-lailatul-fitria-oza-kioza.html

Setiawan, A. R. (2018, Mei 11). Mathematics. Dipetik Mei 2, 2020, dari ALOВАТИІつ: http://alobatnic.blogspot.com/2018/05/mathematics.html

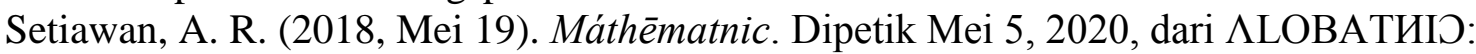
http://alobatnic.blogspot.com/2018/05/mathematnic.html

Setiawan, A. R. (2019). Kurikulum Lokal Madrasah Tasywiquth Thullab Salafiyyah (TBS) Kudus. MI NU TBS Kudus. Kudus: Madrasah Tasywiquth Thullab Salafiyyah (TBS) Kudus.

Setiawan, A. R. (2019, September 28). Menyelaraskan Pendidikan untuk Pembangunan Berkelanjutan dan Pandangan Islam Tradisional. Dipetik Mei 2, 2020, dari ALОВАТИІР: http://alobatnic.blogspot.com/2019/09/menyelaraskan-pendidikanuntuk-pembangunan-berkelanjutan-dan-pandangan-islam-tradisional.html

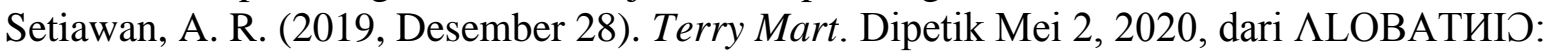
http://alobatnic.blogspot.com/2019/12/terry-mart.html

Setiawan, A. R. (2020, April 27). Fadhilaturrahmi. Dipetik Mei 1, 2020, dari ALOBAТИІР: https://alobatnic.blogspot.com/2020/04/fadhilaturrahmi.html

Setiawan, A. R. (2020, April 21). Lembar Kegiatan Literasi Saintifik untuk Pembelajaran Jarak Jauh Topik Penyakit Coronavirus 2019 (COVID-19). (Fadhilaturrahmi, Penyunt.) Edukatif: Jurnal Ilmu Pendidikan, 2(1), 28-37.

Setiawan, A. R. (2020, Januari 24). Pembelajaran Tematik Berorientasi Literasi Saintifik. (Fadhilaturrahmi, Penyunt.) Jurnal Basicedu, 4(1), 51- 69.

Setiawan, A. R. (2020, Maret 1). Pendidikan Literasi Finansial Melalui Pembelajaran Fiqh Mu'āmalāt Berbasis Kitab Kuning. Nazhruna: Jurnal Pendidikan Islam, 138-159.

Setiawan, A. R. (2020, Maret 1). Pendidikan Literasi Finansial Melalui Pembelajaran Fiqh Mu'āmalāt Berbasis Kitab Kuning. Nazhruna: Jurnal Pendidikan Islam, 138-159.

Setiawan, A. R. (2020). Penggunaan Mabadi 'Asyroh dalam Pembelajaran Biologi untuk Meningkatkan Motivasi dan Hasil Belajar. Prosiding Seminar Nasional Biologi 2019 Inovasi Penelitian dan Pembelajaran Biologi III (IP2B III) (hal. 158-164). Surabaya: Universitas Negeri Surabaya (UNESA).

Setiawan, A. R. (2020, April 29). Praktik Penerbitan Ketinggalan Zaman. Dipetik Mei 5, 2020, dari АLОВАТИІО: http://alobatnic.blogspot.com/2020/04/praktik-penerbitanketinggalan-zaman.html

Setiawan, A. R. (2020, Mei 1). Reading Academic Articles. Dipetik Mei 2, 2020, dari АLОВАТИІО: http://alobatnic.blogspot.com/2020/05/reading-academic-articles.html

Setiawan, A. R., Puspaningrum, M., \& Umam, K. (2019, Desember 6). Pembelajaran Fiqh Mu'āmalāt Berorientasi Literasi Finansial. Tarbawy: Indonesian Journal of Islamic Education, 6(2), 187-102.

Setiawan, A. R., Utari, S., \& Nugraha, M. G. (2016). Mengonstruksi Rancangan Soal Domain Kompetensi Literasi Saintifik Siswa SMP Kelas VIII pada Topik Gerak Lurus. 
Seminar Nasional Fisika ke-2 (SiNaFi II). Kota Bandung: Universitas Pendidikan Indonesia (UPI).

Siayah, S. (2016, November 15). Percakapan tentang diksi dalam al-Qur'ān. (A. R. Setiawan, Pewawancara)

Siayah, S., \& Setiawan, A. R. (2020, April 13). A Brief Explanation of Science Education. EdArXiv, 1-12.

Siayah, S., Kurniawati, N. K., \& Setiawan, A. R. (2020, Februari 27). Six Main Principles for Quality Learning based on "Ta'līm al-Muta'allim Țorīq al-Ta'allum”.

ResearchGate.net.

Simpson, E. (1966). The Classification of Educational Objectives in the Psychomotor Domain. Urbana: University of Illinois at.

SINTA. (2020, April 20). Science and Technology Index - SINTA. Dipetik Mei 5, 2020, dari SINTA: http://sinta.ristekbrin.go.id/journals/detail?id=4083

SIVIL. (2020, Mei 2). SIVIL - DITJEN BELAMAWA - KEMENRISTEKDIKTI. Dipetik Mei 2, 2020, dari SIVIL - DITJEN BELAMAWA - KEMENRISTEKDIKTI: https://ijazah.kemdikbud.go.id/

Sudja, W. A. (1998). Penggunaan OHP Sebagai Upaya Meningkatkan. Mimbar Pendidikan, $17(4), 55-59$.

Sugiyono. (2018). Metode Penelitian Bisnis (3 ed.). Bandung: Alfabeta.

Tim Penyusun. (2016). Pedoman Akademik STKIP Pahlawan Tuanku Tambusai Tahun 2016. Kabupaten Kampar: STKIP Pahlawan Tuanku Tambusai.

Tim Penyusun. (2017). Buku Pedoman Penulisan Karya Ilmiah Universitas Pahlawan Tahun 2017. Kabupaten Kampar: Universitas Pahlawan Tuanku Tambusai.

United States National Bureau of Standards. (1959). Notices "Refinement of values for the yard and the pound". Gaithersburg: United States National Bureau of Standards.

Universitas Pahlawan Tuanku Tambusai. (2017, Februari 29). Jurnal Universitas Pahlawan Tuanku Tambusai. Dipetik Mei 2, 2020, dari Jurnal Universitas Pahlawan Tuanku Tambusai: https://journal.universitaspahlawan.ac.id/

Universitas Pahlawan Tuanku Tambusai. (2019, April 13). Program Studi S1 PGSD Universitas Pahlawan Tuanku Tambusai. Dipetik Mei 1, 2020, dari Universitas Pahlawan Tuanku Tambusai: https://universitaspahlawan.ac.id/id/program-studi-s1pgsd/

Universitas Pahlawan Tuanku Tambusai. (2019, Maret 4). Sejarah Universitas Pahlawan Tuanku Tambusai. Dipetik Mei 2, 2020, dari Universitas Pahlawan Tuanku Tambusai: https://pgpaud.universitaspahlawan.ac.id/index.php/2019/03/04/sejarah-universitaspahlawan-tuanku-tambusai/

Utama, J. A. (2012, Mei 26). Menyenangi Matematika dan Sains melalui Astronomi. Seminar Nasional "Cakrawala untuk Negeri", hal. 1-7.

Utama, J. A., \& Turmudi. (2012). Menyoal Batas Toleransi Arah Kiblat. Prosiding Seminar Nasional Penelitian, Pendidikan dan Penerapan MIPA (hal. F-1 - F-4). Yogyakarta: Universitas Negeri Yogyakarta.

Wahyudin. (2017, Maret 9). curriculum vitae - Prof. Wahyudin. Dipetik Mei 3, 2020, dari curriculum vitae - Pendidikan Matematika UPI: https://home.matematika.upi.edu/wpcontent/uploads/2018/02/Prof.-Wahyudin.pdf

Walters Art Museum. (2014, April 18). Inscribed Pound Weight. Dipetik Mei 1, 2020, dari Walters Art Museum: https://art.thewalters.org/detail/11026

Yu, C.-f. (2001). Kuan-yin, The Chinese Transformation of Avalokitesvara. New York City: Columbia University Press.

Yulinda, N. (2016). Pengaruh Pendekatan Contextual Teaching and Learning (Ctl) Terhadap Kemampuan Pemecahan Masalah Matematis dan Kepercayaan Diri Siswa Pada 
Materi Volume Kubus dan Balok (Penelitian Eksperimen Terhadap Siswa Kelas V SDN Palasah dan SDN Mandalaherang I di Ke. Bandung: Universitas Pendidikan Indonesia (UPI).

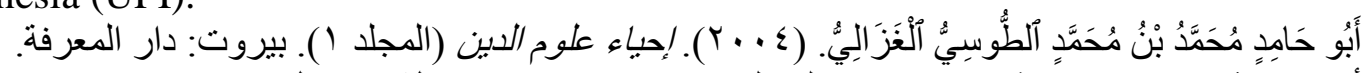

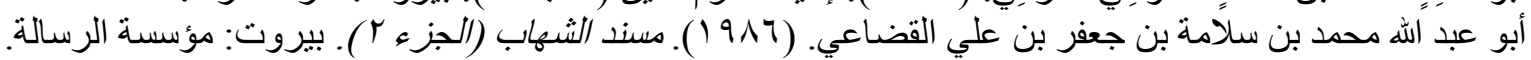

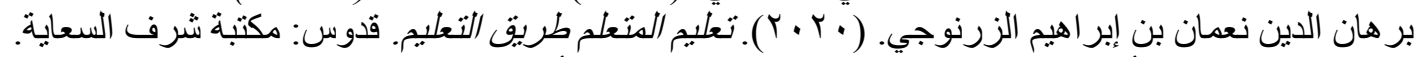

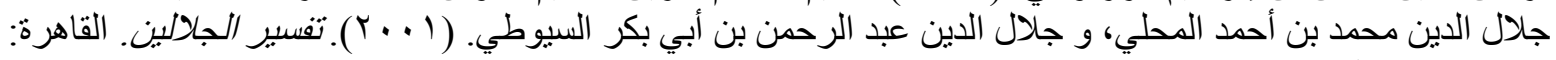

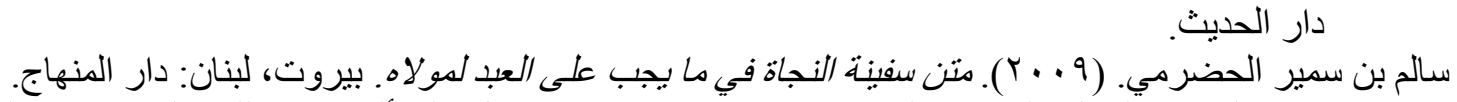

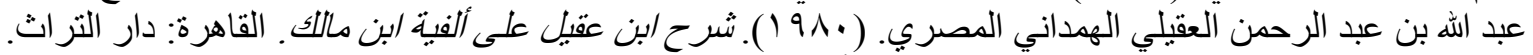

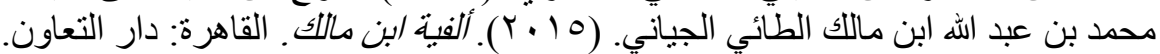

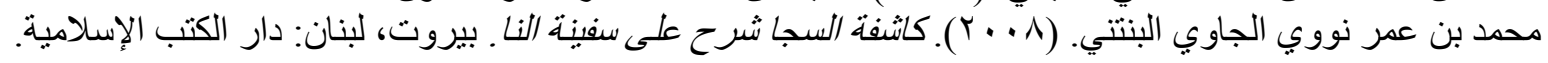

